\title{
Effect of rib roughness pitch on thermal and thermo-hydraulic performance of a solar air heater roughened artificially with arc rib having gap
}

\author{
V.S. Hans ${ }^{1}$, R. S. Gill ${ }^{2 *}$ and Rupinderpal Singh ${ }^{2}$ \\ ${ }^{1}$ School of Energy Studies for Agriculture, Punjab Agricultural University, Ludhiana (PB.), INDIA \\ ${ }^{2}$ Department of Mechanical Engineering, Punjab Agricultural University, Ludhiana (PB.), INDIA \\ * Corresponding author. E-mail: rsgill@pau.edu
}

Received: June 10, 2015; Revised received: October 27, 2015; Accepted:December 26, 2015

\begin{abstract}
This experimental study on a solar air heater having absorber plate roughened artificially by providing roughness in the form of arc ribs having gap was carried out in the Department of Mechanical Engineering, Punjab Agricultural University, Ludhiana, India to study the effect of relative roughness pitch on thermal and thermohydraulic performance as well as to compare the performance of arc rib with gap roughened solar air heater with that of continuous arc rib roughened solar air heater. The roughness geometry parameters included relative roughness height of 0.043 , angle of attack of 30 degree, relative gap position of 0.80 , gap-width equal to the width of the rib and five values of relative roughness pitch ranging from 4 to 12 for flow Reynolds number range of 2000 to 16,000. The Nusselt number and friction factor were found to be more for relative roughness pitch value of 10 as compared to other values of relative roughness pitch. Thermo-hydraulic performance of solar air heaters roughened by arc with gap and continuous arc roughness geometries were found to be 1.91 times and 1.78 times respectively as compared to that of solar air heater having smooth absorber plate due to generation of turbulence in laminar sublayer region. However, improvement in thermo-hydraulic performance of solar air heater roughened by arc with gap geometry over continuous arc rib roughened solar air heater was attributed to generation of a region of turbulence on downstream side of the gap.
\end{abstract}

Keywords: Artificial roughness, Reynolds number, Solar air heater, Thermal performance, Thermo-hydraulic performance

\section{INTRODUCTION}

Thermal performance of a solar air heater is poor because of low heat transfer coefficient between the absorber plate and air which leads to higher absorber plate temperature and hence greater amount of heat losses to the surroundings (Duffie and Beckman, 2006). A number of experimental investigations have been reported in literature in which different methods have been used to improve the thermal performance of solar air heaters (Ho CD et al., 2009; Akpinar and Koçyig, 2010; Alta et al., 2010; Omojaro and Aldabbagh, 2010; Siddhartha, 2010; Wazed et al., 2010; ElSebaii et al., 2011; Gill et al., 2012). In most of the performance improvement methods, enhancement in thermal performance is accompanied by large pumping power requirements due to increased frictional losses. However, use of artificial roughness on the underside of the absorber plate of solar air heater brings considerable enhancement in thermal performance at nominal increase in frictional losses (Bhushan and Singh, 2010; Hans et al., 2010; Singh et al., 2011, Singh et al., 2015). Gupta et al. (1993) carried out an experimental investigation to compare the thermal performance of solar air heaters having absorber plates roughened artificially with inclined and transverse rib type roughness. It was reported that inclined ribs outperform the transverse ribs due to generation of rotating secondary flow cell resulting in increase in local heat transfer. Han and Park (1988) and Park et al. (1992) also investigated the thermal performance of inclined ribs and reported that heat transfer enhancement in channels having inclined ribs was found to be significantly greater than that of channels having transverse ribs. With the focus of rib roughness shifted to high performance ribs, Momin et al. (2002) reported that $\mathrm{V}$-shape rib perform better that inclined ribs due to generation of two rotating secondary flow cells. Hans et al. (2010) reported that multiple V-ribs improve thermal performance considerably as compared to single V-rib due to generation of more number of rotating secondary flow cells. Kumar et al. (2012) reported that multiple V-rib with gap outperform continuous multiple V-rib in terms of heat transfer enhancement due to generation of more number of secondary flow cells and interruption of growth of boundary layer downstream of a rib as secondary flow passes through the gap. Aharwal et al. (2009) and Singh et al. (2011) also reported that gap in inclined rib as well as in single V-rib brings out considerable 
improvement in thermal performance as compared to continuous inclined rib and continuous single V-rib respectively. However, thermal and thermo-hydraulic performances of solar air heater having absorber plate roughened with arc rib with gap have not been evaluated. Therefore, an experimental investigation has been carried out to study the thermal and thermo-hydraulic performances of solar air heater roughened with arc rib with gap. In order to bring out the effect of gap in arc rib, thermal and thermo-hydraulic performances of solar air heater having arc rib with gap type of roughness have been compared with those of solar air heater having continuous arc rib type roughness.

\section{MATERIALS AND METHODS}

Experimental set-up and procedure: An experimental test facility has been designed and fabricated in the Department of Mechanical Engineering, Punjab Agricultural University, Ludhiana, India. The roughened plates having different values of relative roughness pitch of arc rib with gap geometry were tested to study the effect of relative roughness pitch on the heat transfer and fluid flow characteristics of a rectangular duct of a solar air heater. A schematic diagram of experimental setup is shown in Fig. 1.It consists of a rectangular duct having entry, test and exit sections, a 3-phase centrifugal blower with two control valves to pass and control airflow through the duct, a calibrated orifice plate for measurement of mass flow rate of air, a digital micro manometer for measuring pressure drop across the duct and digital temperature indicator for temperature measurement. The rectangular duct is made of wood and is $2440 \mathrm{~mm}$ long with a flow cross section of $300 \mathrm{~mm}$ wide (W) and $25 \mathrm{~mm}$ deep (H) and has entry section, test section and exit section of lengths of $550 \mathrm{~mm}, 1000 \mathrm{~mm}$ and $890 \mathrm{~mm}$ respectively in accordance with the recommendation of ASHRAE standard 93-77 (1977). The top side of the rectangular duct comprises $1 \mathrm{~mm}$ thick galvanized iron sheet roughened with circular cross section aluminum ribs whereas the remaining three walls are kept smooth and insulated. The absorber plate is heated from the top by supplying a constant heat flux by means of an electrical heater topped by an insulation of $50 \mathrm{~mm}$ thick glass wool and $12 \mathrm{~mm}$ thick plywood. A calibrated orifice meter connected with a U- tube manometer having kerosene as manometric fluid is used to measure the mass flow rate of air. Calibrated copper-constantan 0.3 $\mathrm{mm}$ diameter (24 SWG) thermocouples have been used for measurement of inlet and outlet air, and the absorber plate temperatures. The pressure drop across the test section was measured by digital micro-manometer having a least count of $0.001 \mathrm{~Pa}$. Data has been collected under study-state condition which was obtained in about 1.5 to 2 hours. In order to determine the effectiveness of arc rib with gap geometry, Nusselt number and friction factor of a conventional solar air heater having smooth absorber plate and a solar air heater roughened with continuous arc rib were determined experimentally and compared with those of a solar air heater roughened with arc rib with gap under similar operating conditions.

Roughness geometry and range of parameters : Fig. 2 shows the general arrangement of arc-shaped rib with gap. The aluminum wires were fixed on the underside of absorber plates to develop $30^{\circ}$ arc ribs with gap. The roughness geometry and flow parameters considered in this experimental study are listed in Table 1.

\section{Data reduction}

The heat transfer rate $\left(\mathrm{Q}_{\mathrm{u}}\right)$ to air is given by:

$$
Q_{u}=r_{\digamma} \ldots \quad{ }_{i} \text { ) }
$$

where,

$\mathrm{m}$ mass flow rate of air, $\mathrm{kg} / \mathrm{s} ; \mathrm{C}_{\mathrm{p}}$ specific heat of air at constant pressure, $\mathrm{J} / \mathrm{kg}-\mathrm{K}$;

$\mathrm{T}_{\mathrm{i}}$ inlet air temperature, ${ }^{\circ} \mathrm{C}$;

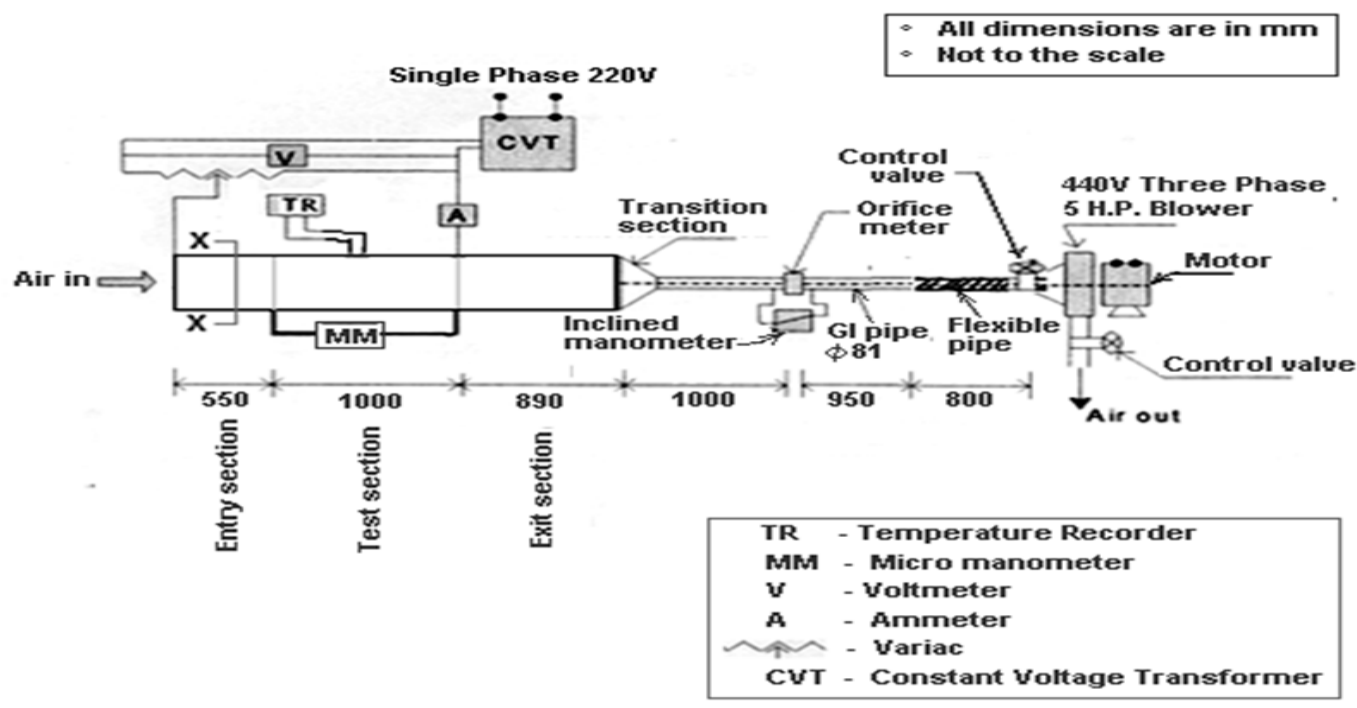

Fig. 1. Schematic of Experimental setup. 


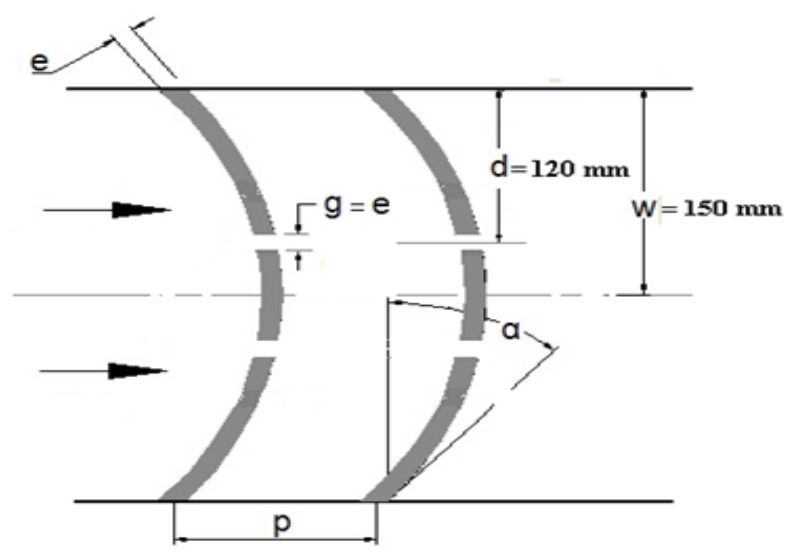

Fig. 2. General arrangement of arc-shaped rib with gap.

$\mathrm{T}_{\mathrm{o}}$ average outlet air temperature, ${ }^{\circ} \mathrm{C}$;

The convective heat transfer coefficient (h) and Nusselt number $(\mathrm{Nu})$ for the heated test section is calculated from the relationships as given below:

$$
h=\frac{Q_{u}}{A_{p}\left(T_{p m}-T_{f m}\right)} \quad \text { and } \quad N u=\frac{h D_{h}}{K_{a i r}}
$$

where,

$\mathrm{T}_{\mathrm{pm}}$ and $\mathrm{T}_{\mathrm{fm}}$ are the plate mean temperature and the fluid mean temperature respectively, ${ }^{\circ} \mathrm{C}$;

$\mathrm{A}_{\mathrm{p}}$ absorber plate area, $\mathrm{m}^{2}$;

$\mathrm{D}_{\mathrm{h}}$ hydraulic diameter of duct, $\mathrm{m}$;

$\mathrm{K}_{\text {air }}$ thermal conductivity of air, $\mathrm{W} / \mathrm{m}-\mathrm{K}$.

Pressure drop $(\delta \mathrm{P})$ measured across the test section length $\left(\mathrm{L}_{\mathrm{f}}\right)$ is used to find out the friction factor $(\mathrm{f})$ using the equation:

$$
f=\frac{2(\delta P) \rho_{\text {air }} D_{h}}{4 L_{f} G_{\text {air }}{ }^{2}}
$$

where,

$\mathrm{G}_{\text {air }}$ mass velocity of air, $\mathrm{kg} / \mathrm{s}-\mathrm{m}^{2}$;

$\rho_{\text {air }}$ density of air, $\mathrm{kg} / \mathrm{m}^{3}$

Based on the analysis of errors in the experimental measurements for different instruments used (Kline and McClintock, 1953), the uncertainties in the values of the Reynolds number, Nusselt number and friction factor have been estimated to be $\pm 2.22 \%$, $\pm 2.49 \%$ and $\pm 6.81 \%$, respectively for Reynolds number value of 2000 and corresponding values for Reynolds number value of 16000 are $\pm 1.57 \%, \pm 4.28 \%$ and $\pm 3.48 \%$ respectively.

Validation of experimental setup: For validation of experimental setup, Nusselt number and friction factor determined from experimental data for smooth duct have been compared with the values obtained from Equation [4] and Equation [5] for Nusselt number and friction factor, respectively.

Dittus Boelter Equation: Nus $=0.023 \operatorname{Re}^{0.8} \operatorname{Pr}^{0.4}$ (4)

Modified Blasius Equation: $\mathrm{fs}=0.085 \mathrm{Re}^{-0.25}$

The comparison of the experimental and predicted values of Nusselt number and friction factor is shown
Table 1. Values of flow and roughness geometry parameters.

\begin{tabular}{cll}
\hline S. No. & Parameters & Range \\
\hline i & Reynolds Number $(\mathrm{Re})$ & 2000 to 16000 \\
ii & Relative roughness height $\left(\mathrm{e} / \mathrm{D}_{\mathrm{h}}\right)$ & 0.043 \\
iii & Relative roughness pitch $(\mathrm{p} / \mathrm{e})$ & 4 to 12 \\
iv & Arc-angle $(\alpha)$, degree & $30^{\circ}$ \\
v & Relative gap position $(\mathrm{d} / \mathrm{w})$ & 0.8 \\
vi & Relative gap width $(\mathrm{g} / \mathrm{e})$ & 1.0
\end{tabular}

in Figs. 3 and 4 respectively. The average deviation of experimental values of Nusselt number is $\pm 3.9 \%$ from the predicted values given in Eq. 4 and the average deviation of experimental values of friction factor is $\pm 2.5 \%$ from the predicted values given by Eq. 5 . This shows good agreement between experimental and predicted values, which ensures the accuracy of the data collected with the experimental set-up.

\section{RESULTS AND DISCUSSION}

In this section, the variation of Nusselt number, friction factor and thermo-hydraulic performance parameter of duct roughened with arc rib having gap as a function of Reynolds numbers have been plotted and compared with those of the continuous arc rib roughened duct under similar operating conditions.

Figs. 5 (a) and (b) show the effect of Reynolds number on Nusselt number and friction factor for various values of relative roughness pitch, $\mathrm{p} / \mathrm{e}$, relative roughness height, e/ $D_{h}$ value of 0.043 , relative gap width, $g / e$, value of 1.0 , relative gap position, $\mathrm{d} / \mathrm{w}$, value of 0.8 and angle of attack value of $30^{\circ}$. It was observed that the Nusselt number increased with the increase in Reynolds number for all the values relative roughness pitch considered in this experimental investigation for both arc rib with a gap and conventional solar air heater having smooth absorber plate. This can be attributed to the fact that turbulence increased with increase in Reynolds number (Singh et al., 2015).For the entire range of Reynolds number, Nusselt number was found to be higher for arc rib with a gap as compared to conventional solar air heater having smooth absorber plate. From Fig. 5(b), it was observed that the friction factor decreased with increase in Reynolds number for all values of relative roughness pitch ( $\mathrm{p} / \mathrm{e})$ and this can be attributed to the fact that thickness of viscous sub-layer decreases with increase in Reynolds number.

In order to show the effect of relative roughness pitch (p/e)on Nusselt number and friction factor, the results shown in Figs. 5 (a) and (b)have been re-plotted in Figs. 6 (a) and (b) for different values of Reynolds number. It was observed that as relative roughness pitch increased from 4 to 10, Nusselt number and friction factor increased and then both decreased with further increase in relative roughness pitch from 10 to 12 . This variation may be caused by change in flow and heat transfer characteristics of secondary flow at front side of rib. The results are in agreement with previous 


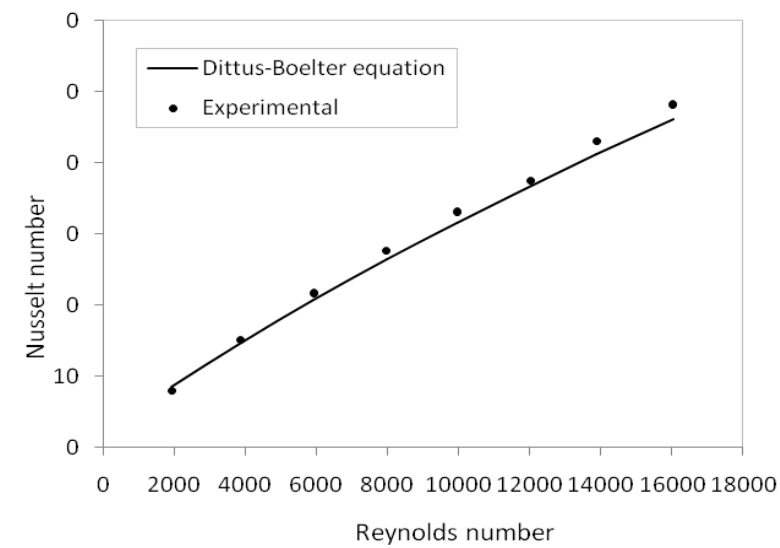

Fig. 3. Comparison of experimental and predicted values of Nusselt number.

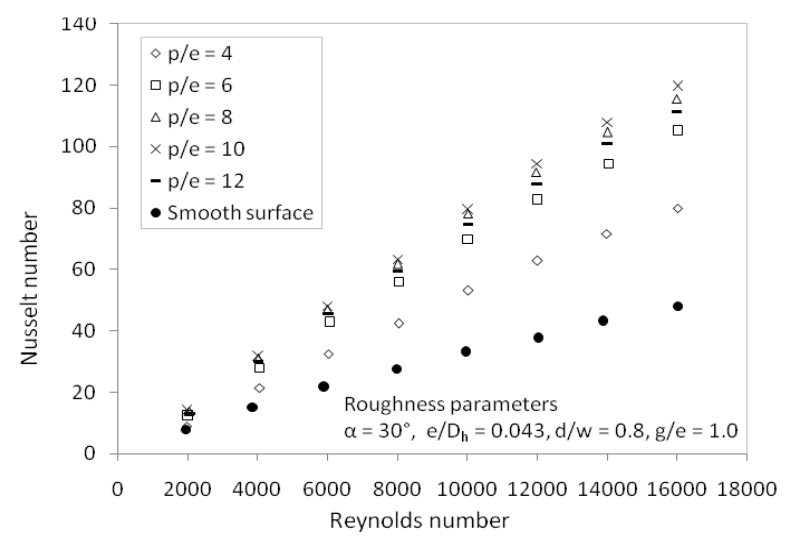

(a)



Fig. 4. Comparison of experimental and predicted values of friction factor.

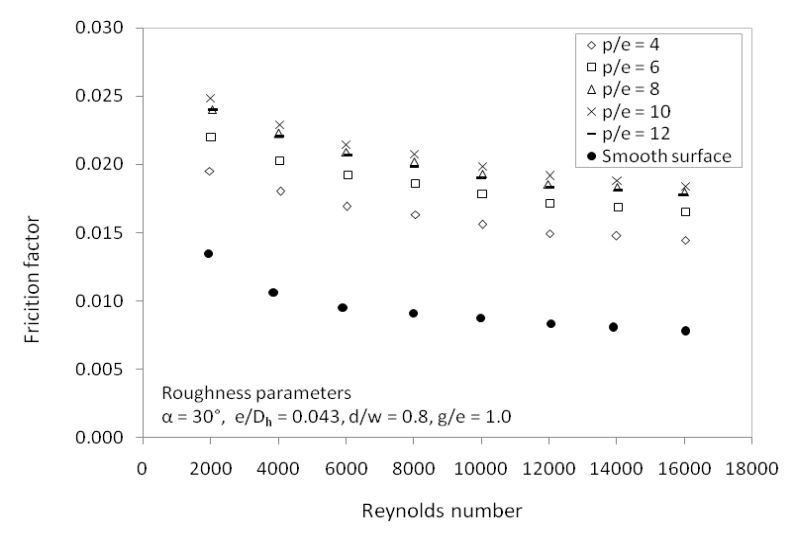

(b)

Fig. 5. Variation of Nusselt number (Nu) and friction factor (f) as a function of Reynolds number (Re).



(a)

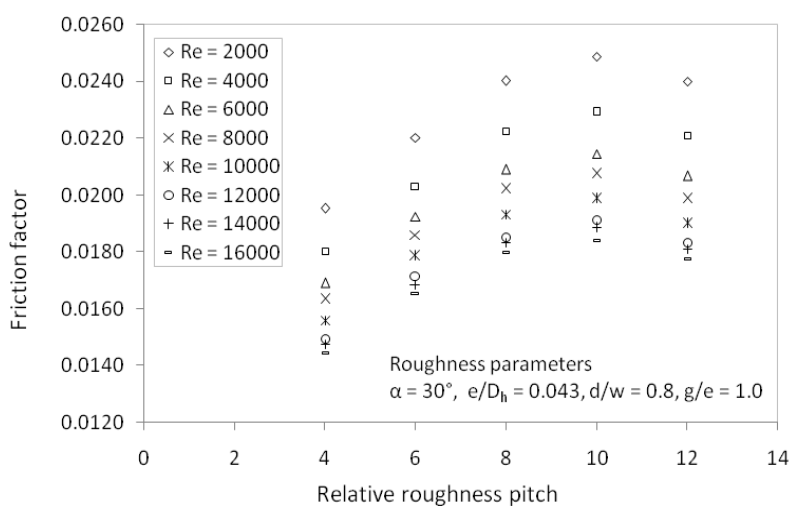

(b)

Fig. 6. Variation of Nusselt number (Nu) and friction factor ( $f$ ) as a function of relative roughness pitch (p/e).

investigation carried out by Han et al., 1978.

It can be seen from Fig. 5 (a) that the solar air heater roughened with arc rib with gap resulted in higher Nusselt number and friction factor as compared to smooth conventional solar air heater duct. Therefore, it is pertinent to determine the optimum values of roughness geometry parameters of arc rib with gap that will result in maximum enhancement of heat transfer with minimum frictional losses. For this purpose, thermo-hydraulic performance of a solar air heater, roughened with arc rib having gap, has been evaluated in terms of thermo-hydraulic performance parameter, $\eta$ proposed by Eckert (1972). Thermo-hydraulic performance parameter is given by the following equation: $\eta=(\mathrm{Nu} / \mathrm{Nus}) /(\mathrm{f} / \mathrm{fs})^{1 / 3}$

The value of thermo-hydraulic performance parameter greater than unity indicates it is overall advantageous to use roughened duct in comparison to smooth duct. 


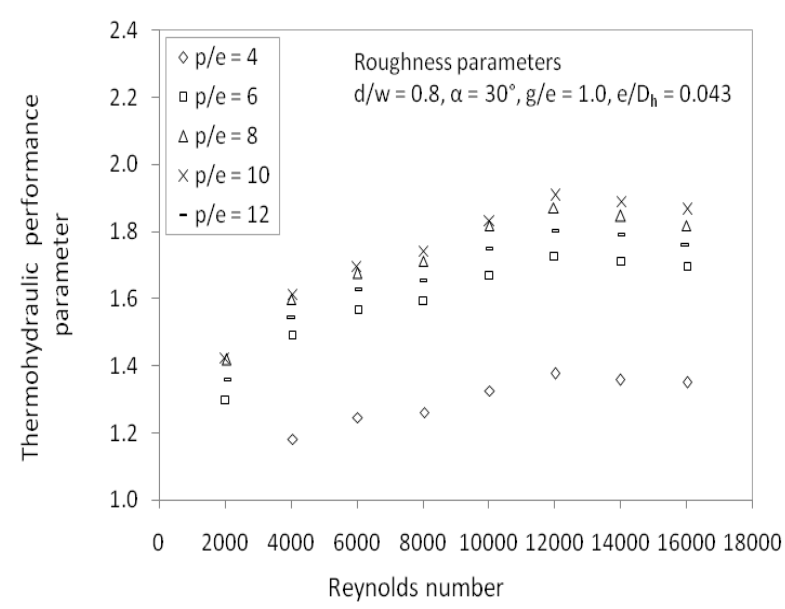

Fig. 7.Variation of Thermo-hydraulic performance parameter $(\eta)$ as a function of Reynolds number (Re) for different relative roughness pitch (p/e).

Fig. 7 has been plotted to show the variation of thermo -hydraulic performance parameter for different values of relative roughness pitch as a function of Reynolds number. For all values of relative roughness pitch, value of thermo-hydraulic performance parameter has been found to be more than unity which clearly indicates the superior performance of arc rib with gap in comparison to the smooth duct. The highest value of thermo-hydraulic performance parameter was observed to be 1.91 at Reynolds number of 12,000 for relative roughness pitch of 10 . This indicates that it is advantageous to use arc rib with gap with relative roughness pitch of 10 as compared to other values of relative roughness pitch.

In order to bring out the advantage gained by using gap in continuous arc rib, results of present study have been compared with continuous arc rib tested under similar operating and roughness geometry parameters. Thermal performance, in terms of Nusselt number, frictional characteristics, in terms of friction factor and thermo-hydraulic performance, in terms of thermohydraulic performance parameter, of solar air heaters

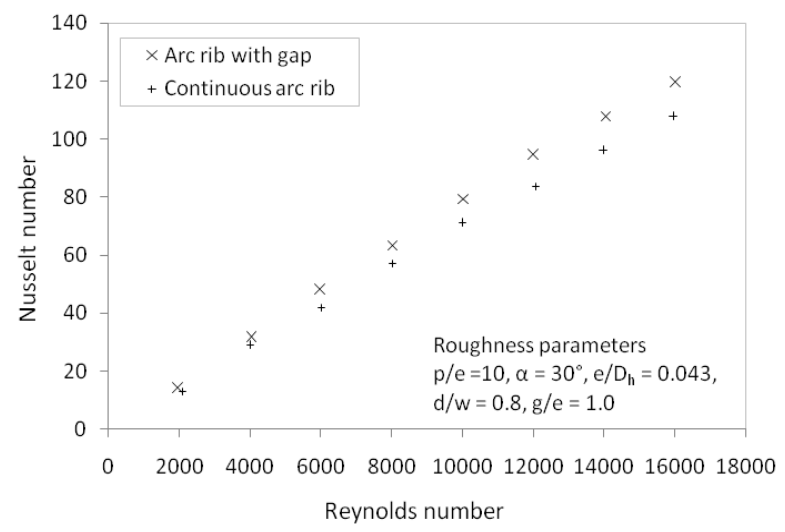

(a) roughened with arc rib having gap and continuous arc rib have been compared.

Figs. 8 (a) and (b) have been plotted to compare Nusselt number and friction factor of solar air heater roughened with arc rib having gap with those of solar air heater roughened with continuous arc rib. For all the values of Reynolds number, Nusselt number and friction factor for arc rib having gap were found to be more as compared to those of continuous arc rib. For arc rib having gap, the highest values of Nusselt number and friction factor were found to be 1.10 times and 1.08 times respectively as compared to continuous arc rib. Similarly, in Fig. 9 it has been shown that for all values of Reynolds number, thermo-hydraulic performance parameter was found to be higher in case of arc rib with gap as compared to continuous arc rib. For arc rib having gap, the highest thermo-hydraulic performance parameter obtained is 1.91 at relative roughness pitch of 10 , as compared to 1.78 for continuous arc rib. It is due to the fact that with the introduction of gap in a continuous arc rib, a region of high local Nusselt number develops downside of the gap as the air flow through the gap accelerates and causes flow-mixing and turbulence on downstream side of the gap as reported by Cho et al. (2003). Similar findings have been reported by Aharwal et al. (2009) for inclined ribs with gap, Singh et al. (2011) for V rib with gap and Kumar et al. (2012) for multi V rib with gap.

\section{Conclusion}

It was concluded that the friction factor and Nusselt number of the roughened duct are strong function of rib roughness pitch. The highest friction factor and Nusselt number occur at relative rib roughness pitch value of 10 and they decrease on both sides of this pitch. For arc rib having gap, the highest values of Nusselt number and friction factor were found to be 1.10 times and 1.08 times respectively as compared to continuous arc rib. Under similar experimental conditions, the arc rib having gap produces higher thermo-

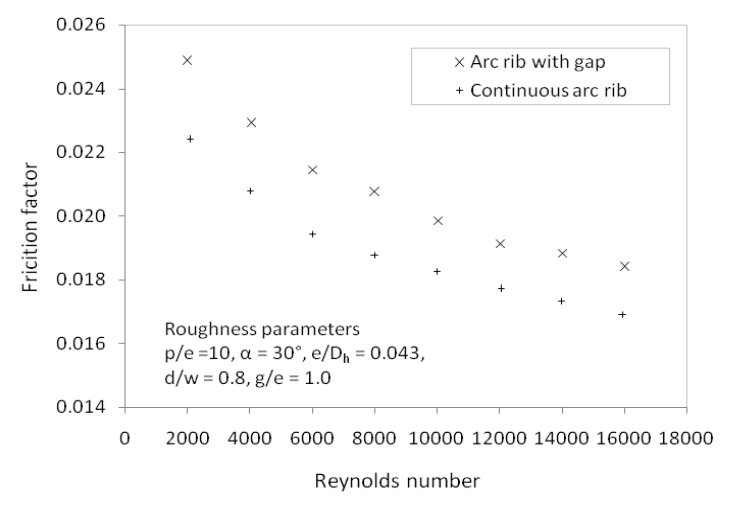

(b)

Fig. 8. Comparison of variation in Nusselt number (Nu) and friction factor (f) of solar air heater duct roughened with arc rib having gap and continuous arc rib. 


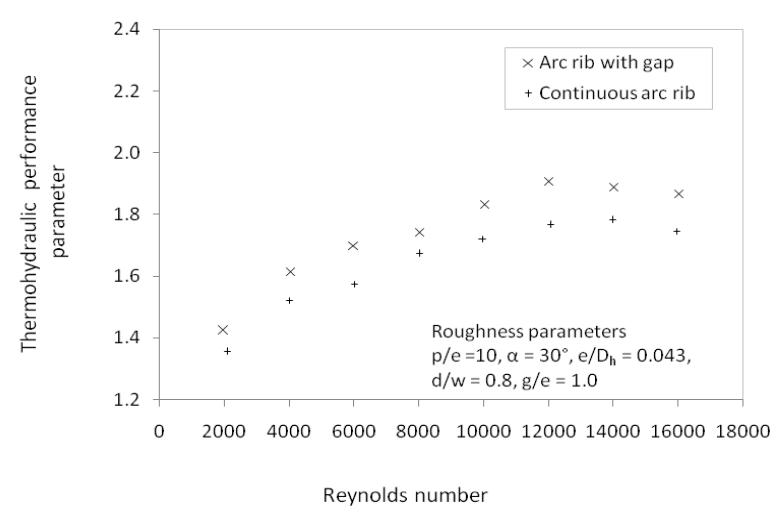

Fig. 9. Comparison of variation in thermo-hydraulic performance parameter ( $\eta$ ) of solar air heater duct roughened with arc rib having gap and continuous arc rib.

hydraulic performance in comparison to continuous arc rib. Corresponding to relative roughness pitch value of 10 , the highest value of thermo-hydraulic performance parameter obtained for arc rib having gap is 1.91 as compared to 1.78 for continuous arc rib for Reynolds number value of 12000 . The improvement in thermohydraulic performance of solar air heater roughened by using arc with gap geometry over continuous arc rib roughened solar air heater is due to generation of a region of turbulence on downstream side of the gap.

\section{ACKNOWLEDGEMENTS}

The authors acknowledge the University Grants Commission (UGC)- India for financially supporting this research work and Punjab Agricultural University for providing facilities to carry out this research .

\section{REFERENCES}

Aharwal, K.R., Gandhi, B.K. and Saini, J.S. (2009). Heat transfer and friction characteristics of solar air heater ducts having integral inclined discrete ribs on absorber plate. Int. J Heat Mass Transfer. 52: 5970-5977.

Akpinar, E.K. and Koçyig, it F. (2010). Energy and exergy analysis of a new flat-plate solar air heater having different obstacles on absorber plates. Appl. Energy. 87: $3438-3450$.

Alta, D., Bilgili, E., Ertekin, C. and Yaldiz, O. (2010). Experimental investigation of three different solar air heaters: energy and exergy analyses. Appl. Energy. 87: 2953-2973.

ASHRAE, Standard 93-97, 1977. Method of Testing to determine the thermal performance of solar air heater, American Society for Heating, Refrigeration and Air Conditioning Engineering, NY: 1-34.

Bhushan, B. and Singh, R. (2010). A review on methodology of artificial roughness used in duct of solar air heaters. Energy. 35: 202-212.

Cho, H.H., Kim, Y.Y., Rhee, D.H., Lee, S.Y., Wu S.J. and Choi, C. (2003). The effect of gap position in discrete ribs on local heat mass transfer in a square duct. $J$. of Enhanc. Heat Transf. 10 (3): 287-300.

Duffie, J.A. and Beckman, W.A. (2006). Solar engineering of thermal processes. John Wiley and Sons, New York.
Eckert, E.R.G. and Webb, R.L. (1972). Application of rough surfaces to heat exchanger design. Int. J. Heat and Mass Transfer. 15: 1647-1658.

El-Sebaii, A.A., Aboul-Enein, S., Ramadan, M.R.I., Shalaby, S.M. and Moharram, B.M. (2011). Thermal performance investigation of double pass-finned plate solar air heater. Appl. Energy. 88: 1727-1239.

Gill, R. S., Singh, S and Singh, P.P. (2012). Low cost solar air heater. Energy Conversion and Management. 57(5): 131-142.

Gupta, D., Solanki, S.C. and Saini, J.S. (1993) Heat and fluid flow in rectangular solar air heater ducts having transverse rib roughness on absorber plates. Solar Energy. 51(1): $31-37$

Han, J.C. and Park, J.S. (1988). Developing heat transfer in rectangular channels with rib turbulators. Int. J. Heat and Mass Transfer, 31, 183-195.

Han, J.C., Glicksman, L.R. and Rohsenow, W.M. (1978). An investigation of heat transfer and friction for rib-roughened surfaces. Int. J. Heat and Mass Transfer. 21, 1143-1156.

Hans, V.S., Saini, R.P. and Saini, J.S. (2010). Heat transfer and friction correlations for a solar air heater duct roughened artificially with multiple v-ribs. Solar Energy. 84: 898-911.

Ho, C.D., Yeh, H.M., Cheng, T.W., Chen, T.C. and Wang, R.C. (2009). The influences of recycle on performance of baffled double-pass flat-plate solar air heaters with internal fins attached. Appl. Energy. 86: 1470-1478.

Kline, S.J. and McClintock, F.A. (1953). Describing uncertainties in Single-Sample Experiments. Mechanical Engineering. 75: 3-8

Kumar, Anil, Saini, R.P. and Saini, J.S. (2012) Experimental investigation on heat transfer and fluid flow characteristics of air flow in a rectangular duct with Multi v-shaped rib with gap roughness on the heated plate. Solar Energy. 86: $1733-1749$.

Momin, A.M.E, Saini, J.S. and Solanki, S.C. (2002). Heat transfer and friction in solar air heater duct with $\mathrm{V}$-shaped rib roughness on absorber plate. Int. J. Heat and Mass Transfer 45: 3383-3396.

Omojaro, A.P. and Aldabbagh, L.B.Y. (2010). Experimental performance of single and double pass solar air heater with fins and steel wire mesh as absorber. Appl. Energy. 87: 3759-3765.

Park, J.S., Han, J.C., Huang, Y., Ou, S. and Boyle, R.J. (1992). Heat transfer performance comparisons of five different rectangular channels with parallel angled ribs. Int. J. Heat and Mass Transfer. 35(11): 2891-2903.

Siddhartha, Varun (2010). Thermal performance optimization of a flat plate solar air heater using genetic algorithm. Appl. Energy. 87:1793-1799.

Singh, S., Chander, S. and Saini, J.S. (2011). Heat transfer and friction correlation of a solar air heater ducts artificially roughened with discrete v-down ribs, Energy. 36: 5063-5064.

Singh, S., Singh, B., Hans, V.S.and Gill, R.S. (2015). CFD (computational fluid dynamics) investigation on Nusselt number and friction factor of solar air heater duct roughened with non-uniform cross-section transverse rib. Energy. 84: 509-517.

Wazed, M.A., Nukman, Y., Islam, M.T. (2010) Design and fabrication of a cost effective solar air heater for Bangladesh. Appl. Energy. 87: 3030-2036. 